\title{
TRÍPLICES MUNDOS: \\ Uma leitura da obra Ópera dos mortos, de Autran Dourado
}

\author{
Margarete Hülsendeger
}

Submetido em 29 de maio de 2018.

Aceito para publicação em 04 de outubro de 2018.

Cadernos do IL, Porto Alegre, n. ${ }^{\circ}$ 57, novembro de 2018. p. 153- 165

\section{POLÍTICA DE DIREITO AUTORAL}

Autores que publicam nesta revista concordam com os seguintes termos:

(a) Os autores mantêm os direitos autorais e concedem à revista o direito de primeira publicação, com o trabalho simultaneamente licenciado sob a Creative Commons Attribution License, permitindo o compartilhamento do trabalho com reconhecimento da autoria do trabalho e publicação inicial nesta revista.

(b) Os autores têm autorização para assumir contratos adicionais separadamente, para distribuição não exclusiva da versão do trabalho publicada nesta revista (ex.: publicar em repositório institucional ou como capítulo de livro), com reconhecimento de autoria e publicação inicial nesta revista.

(c) Os autores têm permissão e são estimulados a publicar e distribuir seu trabalho online (ex.: em repositórios institucionais ou na sua página pessoal) a qualquer ponto antes ou durante o processo editorial, já que isso pode gerar alterações produtivas, bem como aumentar o impacto e a citação do trabalho publicado.

(d) Os autores estão conscientes de que a revista não se responsabiliza pela solicitação ou pelo pagamento de direitos autorais referentes às imagens incorporadas ao artigo. A obtenção de autorização para a publicação de imagens, de autoria do próprio autor do artigo ou de terceiros, é de responsabilidade do autor. Por esta razão, para todos os artigos que contenham imagens, o autor deve ter uma autorização do uso da imagem, sem qualquer ônus financeiro para os Cadernos do IL.

\section{POLÍTICA DE ACESSO LIVRE}

Esta revista oferece acesso livre imediato ao seu conteúdo, seguindo o princípio de que disponibilizar gratuitamente o conhecimento científico ao público proporciona sua democratização. 


\title{
TRÍPLICES MUNDOS: \\ Uma leitura da obra Ópera dos mortos, de Autran Dourado
}

\author{
TRIPLE WORDS: \\ A reading of the work Ópera dos mortos, by Autran Dourado
}

Margarete Hülsendeger*

\begin{abstract}
A leitura é o pharmacon, o "remédio" pelo qual a significação do texto é 'resgatada' do estranhamento da distanciação e posta numa proximidade que suprime e preserva a distância cultural e inclui a alteridade na ipseidade" (RICOEUR, 1976, p. 55).

RESUMO: Neste artigo será realizada a análise do romance Ópera dos mortos, de Autran Dourado (1926-2012), tendo como principal fundamentação teórica as ideias expressas pelo filósofo francês Paul Ricoeur (1913-2005) em duas de suas mais importantes obras, Teoria da Interpretação e Tempo e Narrativa. Procurar-se-á demonstrar que a narrativa do escritor mineiro está em sintonia com a operação de configuração que Ricoeur denominou de "tríplice mimese". Para demonstrar a presença de um tríplice tempo - pré-configuração (mimese I), configuração (mimese II) e refiguração (mimese III) -, serão examinados os três "mundos" que fazem parte desse processo: o referencial, o do texto e o do leitor.
\end{abstract}

PALAVRAS-CHAVE: Autran Dourado; Paul Ricoeur; tríplice mimese; narrativa.

ABSTRACT: In this article will be analyzed the novel Opera dos mortos by Autran Dourado (19262012), whose main theoretical basis, is the ideas expressed by the french philosopher Paul Ricoeur (1913-2005) in two of his most important works, Theory of Interpretation and Time and Narrative. It will be tried to demonstrate that the narrative of the writer of Minas Gerais is in tune with the operation of configuration that Ricoeur denominated of "triple mimesis". To demonstrate the presence of a triple time - preconfiguration (mimesis I), configuration (mimesis II) and refiguration (mimesis III) -, the three "worlds" that form part of this process will be examined: the referential, the text and the reader.

KEYWORDS: Autran Dourado; Paulo Ricoeur; Triple mimesis; narrative.

\section{Introdução}

Ópera, "substantivo feminino; obra dramática musicada, geralmente desprovida de partes faladas, composta de recitativos, árias, coro, às vezes de balé, e acompanhada de orquestra; drama musical" (Dicionário Houaiss). Morto, "substantivo masculino; aquele que morreu" (Dicionário Houaiss). Se combinarmos de forma literal esses dois substantivos, a primeira interpretação poderia ser a de estarmos diante de uma obra dramática, desprovida de partes faladas, acompanhada, quem sabe, por uma orquestra, e na qual seus principais personagens são pessoas que não estão mais vivas. Será essa interpretação a que define o tema do livro Ópera dos mortos? Talvez. No entanto, quando se trata de literatura é sempre importante lembrar que nela várias coisas se especificam ao mesmo tempo e o leitor não é obrigado a escolher qualquer uma delas. Logo, na literatura vamos encontrar um uso positivo e produtivo da ambiguidade

\footnotetext{
* Mestra em Teoria da Literatura pela Pontifícia Universidade Católica do Rio Grande do Sul. Doutoranda em Teoria da Literatura pela Pontifícia Universidade Católica do Rio Grande do Sul (Bolsista CAPES). O presente trabalho foi realizado com apoio da Coordenação de Aperfeiçoamento de Pessoal Nivel Superior - Brasil (CAPES) - Código de Financiamento 001.
} 
(RICOEUR, 1976) e o romance Ópera dos mortos é, sem dúvida, um caso exemplar dessa ambiguidade.

O escritor mineiro Autran Dourado (1926-2012) já foi comparado a Guimarães Rosa justamente por compor "um universo ficcional mítico, no qual a história passa a ser regida pela natureza espiralada do tempo" (SOUZA, 1996, p. 34). Também já foi dito que sua ficção, apesar de ser de agradável leitura, é de difícil interpretação (SANTIAGO, 2012, s/p). Contudo, se pensarmos que um texto escrito se dirige sempre a um leitor desconhecido e, portanto, potencialmente a quem quer que saiba ler (RICOEUR, 1976), vamos observar que "não existe nenhuma necessidade, nenhuma evidência a respeito do que é importante e do que é sem importância" sendo o "próprio juízo da importância uma conjectura" (RICOEUR, 1976, p. 89).

Assim, independente de quaisquer interpretações (ou avaliações), é preciso reconhecer que estamos diante de um autor de notável envergadura. Um escritor que ao longo de 65 anos de trabalho acumulou inúmeros prêmios: Jabuti (1982), Camões (2000), Machado de Assis (2008), entre muitos outros. Além disso, seu romance Ópera dos Mortos foi escolhido pela UNESCO para integrar a Coleção de Obras Representativas da Literatura Universal. Sua morte, em 30 de setembro de 2012, representou, para a literatura brasileira, uma grande perda, pois como bem lembrou Silviano Santiago, quando entramos em um texto de Autran Dourado é como se batêssemos à porta da casa de um parente ou como se entrássemos na casa materna da língua, com a linguagem ficcional brotando no sangue dos nossos legítimos vocabulário e sintaxe, sem nacionalidade e sem uma marca específica do tempo (SANTIAGO, 2012, s/p).

Em Ópera dos mortos vamos encontrar uma obra do discurso na qual são postos em relação um sentido explícito e um sentido implícito. Um romance onde a linguagem é cuidadosamente trabalhada, revelando mundos espectrais e estranhos, nos quais os personagens são arrastados por forças instintivas rumo à destruição. $O$ mundo apresentado nessa obra não é uma simples reduplicação do mundo "lá fora"; é, na verdade, um mundo metamorfoseado no qual o que será nele experimentado não poderá ser transmitido a mais ninguém. Em outras palavras, o leitor de Ópera dos mortos terá de se preparar para vivenciar um acontecimento que pertence a uma corrente de consciência, que não pode se transferir como tal para outra corrente de consciência (RICOEUR, 1976). Trata-se, portanto, de uma experiência individual, já que "construir um texto é construí-lo como um indivíduo" (RICOEUR, 1976, p. 89).

Tendo por base o que até agora foi exposto, neste artigo será realizada a análise do romance Ópera dos mortos, de Autran Dourado, tendo como principal fundamentação teórica as ideias expressas pelo filósofo francês Paul Ricoeur (1913-2005) em duas de suas mais importantes obras, Teoria da Interpretação e Tempo e Narrativa. Procurar-seá demonstrar que a narrativa do escritor mineiro está em sintonia com a operação de configuração que Ricoeur denominou de "tríplice mimese". Para demonstrar a presença de um tríplice tempo - pré-configuração (mimese I), configuração (mimese II) e refiguração (mimese III) -, serão examinados os três "mundos" que fazem parte desse processo: o referencial, o do texto e o do leitor. Para fins de análise, esses "mundos" serão apresentados em separado; no entanto, deve-se compreender que, em uma obra literária, esses mundos se entrelaçam de forma que se referem ao seu locutor ao mesmo tempo que se referem ao mundo. Essa correlação, conforme Ricoeur, não ocorre por acaso, porque "é o locutor que, ao falar, se refere ao mundo" e o "discurso na acção e no uso tem uma referência retrógrada ou anterretrógrada ao locutor e ao mundo" (RICOEUR, 1976, p. 33). 


\section{O mundo de Autran Dourado ou o mundo "de fora"}

Ópera dos mortos foi publicado em 1967, mas antes Dourado já havia publicado Teia (1947), Sombra e exílio (1950), Tempo de amar (1952), Nove histórias em grupos de três (1955) e a Barca dos homens (1961). Na maioria dessas obras ele utilizou o método de composição mítico, de tal maneira que, para Silviano Santiago, o novo na literatura de Autran Dourado estava na ideia do eterno retorno, "na sucessão do dia e da noite, na repetição dos dias e das noites" (SANTIAGO, 2012, s/p). Repetições que também transparecem na concepção de Ópera dos mortos, surgindo como uma estrutura dialógica construída com a finalidade de superar a solidão fundamental do ser humano, transformando-se, assim, em um discurso "mais espiritual, no sentido de que é libertado da estreiteza da situação face a face" (RICOEUR, 1976, p. 42).

Quando Ricoeur reflete sobre a composição de uma narrativa, ele traz em primeiro lugar o conceito de preconcepção de mundo, pois tudo o que configura uma narrativa tem sua origem no mundo, ou seja, está no horizonte de eventos do sujeito que escreve. $\mathrm{O}$ escritor, consequentemente, não constrói o texto do nada, mas a partir das condições de seu tempo, devendo, portanto, ser capaz de "identificar a ação em geral por seus traços culturais" (RICOEUR, 1994, p. 88). Além disso, é preciso que ele tenha uma "competência suplementar", que seria a "aptidão de identificar o que se chama de as mediações simbólicas da ação" (RICOEUR, 1994, p. 88). Desse modo, as narrativas evidenciam uma familiaridade com termos que têm relação com o autor e seu público leitor (RICOEUR, 1994, p. 90). Uma familiaridade que não se limita ao simples uso desses termos na trama conceitual da ação, sendo necessário acrescentar "traços discursivos" que têm a finalidade de criar discursos que possam ser identificados como narrativos (RICOEUR, 1994).

Quais seriam, então, as condições do tempo de Autran Dourado? Que traços discursivos ele traz para a Ópera dos mortos que permitem identificá-los como narrativos?

Além do conteúdo mítico, apontado por Silviano Santiago, vamos perceber na obra de Dourado traços culturais que identificam sua terra natal, Minas Gerais. Assim, não é de estranhar a presença, na narrativa, das voçorocas, grandes buracos de erosão causados pelo fogo e intempéries, em solos onde a vegetação não o protege mais, tornando-o pobre, seco e quimicamente morto. Esse fenômeno geológico - encontrado principalmente na região sul de Minas - é mostrado no romance de tal maneira que chega a assustar um dos personagens, Juca Passarinho, pois parece "coisa do diabo, as goelas da voçoroca, como um castigo comendo a cidade que nem ferida braba" (DOURADO, 1999, p. 77).

Como explica Ricoeur, é "porque existe primeiramente algo a dizer, porque temos uma experiência a trazer à linguagem que, inversamente, a linguagem não se dirige apenas para significados ideais, mas também se refere ao que é” (RICOEUR, 1976, p. 33). Portanto, é natural que o autor mineiro, conhecendo a voçoroca, a traga para compor a sua narrativa. No capítulo "Flor de seda", por exemplo, o mesmo Juca Passarinho sonha com a que existe perto da cidade, um sonho no qual ela assume a forma de profecia, uma intuição de que algo irremediável está para ocorrer em sua vida:

Não era um menino. Mas as voçorocas vinham se juntar à lembrança ainda quente do sonho de há pouco, Seu major Lindolfo lhe deu um tiro bem nos peitos, não valia de nada ele gritar. Se chegasse na beirada dos barrancos das voçorocas, para ver o fundo da grota, a terra cederia sob seus pés, ele era tragado. Um sonho acordado, terrível feito o outro. O carro oscilava, e no embalo, os olhos fechados, era como se dormisse de novo. Os olhos fechados, a visão das voçorocas crescia assustadoramente (DOURADO, 1999, p. 77). 
Do mesmo modo, no ano da publicação de Ópera dos mortos, 1967, Costa e Silva assumia a presidência do Brasil, começando a transição do que era um regime militar difuso para uma ditadura que eliminou o que restava das liberdades públicas e democráticas no país. Assim, também não é estranho que Autran Dourado aborde questões relacionadas às disputas políticas que ocorriam, não só em seu estado natal, mas em todo o Brasil. Disputas nas quais a honra da palavra dada e as amizades, muitas vezes, eram deixadas de lado para que alianças fossem feitas e inimigos fossem neutralizados. Para mostrar esse lado da política brasileira, Dourado dá vida a dois personagens que, mesmo sendo parentes de sangue (pai e filho), não podem ser mais diferentes: Lucas Procópio Honório Cota e João Capistrano Honório Cota. Enquanto o primeiro é "o homem de que a gente se lembra por ouvir dizer, de passado escondido e muito tenebroso, coisas contadas em horas mortas, esfumado, já lenda-já história, lembranças se azulando" (DOURADO, 1999, p. 12), representante de um passado selvagem que deseja ser esquecido, o segundo reúne todas as qualidades de um homem nobre na aparência e no espírito, parecido a "um daqueles cavaleiros antigos, fugidos do Amadis de Gaula ou do Palmerim, quando iam para a guerra armados de cavaleiros" (DOURADO, 1999, p. 20), simbolizando a promessa de um futuro menos sombrio.

Contudo, essas diferenças, aparentemente abissais, acabam fundindo-se na forma da edificação que irá dominar toda a narrativa, o sobrado. João Capistrano, ao remodelar a antiga casa construída por Lucas Procópio, nega-se a apagar a memória do pai, talvez intuindo que nele ainda viva uma parte significativa dessa personalidade que por tantos anos assombrou a cidade: "Não quero mudar tudo, disse. Não derrubo obra de meu pai. $\mathrm{O}$ que eu quero é juntar o meu com o de meu pai. Eu sou ele agora, no sangue, por dentro. A casa tem de ser assim, eu quero. Eu mais ele" (DOURADO, 1999, p. 14). Uma decisão que pode ser interpretada como uma forma de demonstrar a força da tradição e o fato incontestável de que o homem, muitas vezes, é o resultado das ações daqueles que o antecederam.

Mais adiante na história, o sobrado deixa de ser o centro cultural e político da cidade para se tornar uma espécie de prisão. Desiludido com a política, sentindo-se traído por todos aqueles que uma vez o viram como um líder, o coronel Capistrano Honório Cota isola-se no sobrado, dando as costas à cidade e optando por viver, até o dia da sua morte, em meio ao rancor e à ira contida: "O coronel Honório Cota voltou à sua antiga morada para guardar a espada, elmo e couraça, encostou sua lança. Voltou ao que era, ou melhor - ficou mais triste e ensimesmado do que era" (DOURADO, 1999, p. 38-39). Nessa pré-configuração de mundo poderá também se encontrar todo um conjunto de recursos simbólicos que fornecerão um "contexto de descrição para ações particulares" (RICOEUR, 1994, p. 93). Há a presença de uma "intratemporalidade" que rompe com uma representação linear do tempo, "entendida como simples sucessão de agoras" (RICOEUR, 1994, p. 101). Em Ópera dos mortos, o tempo que transcorre dentro do sobrado é um tempo fora do tempo, que pode ser medido, mas por relógios "especiais": o grande e luxuoso "relógioarmário", o relógio de prata comemorativo da Independência com a efígie de José Bonifácio e o relógio de ouro Patek Philip, do coronel João Honório Cota. Os três estão parados, marcando as horas da morte, de forma que deles se escutava apenas "as batidas do silêncio" (DOURADO, 1999, p. 42). Contudo, Dourado não esquece que fora da casa o tempo continuava a correr e, para marcar esse que é o "tempo do calendário", o autor introduz a "pêndula", relógio que ao ser conhecido de todos não ocupa os espaços nobres da casa, seu lugar é a copa, a antessala da cozinha, lugar onde permanece fazendo o seu "trabalho de aranha" (DOURADO, 1999, p. 42) até o momento em que ele também deverá ser parado. 
O mundo de Autran Dourado é, portanto, um mundo no qual a "imaginação artística dança com naturalidade, ao ritmo da valsa ou da modinha que exala dos vocábulos e das sentenças cadenciados pela tradição" (SANTIAGO, 2012, s/p). Um mundo construído a partir das mais diferentes influências: de José de Alencar a Machado de Assis, de Gustave Flaubert, passando por Henry James, até William Faulkner. Um mundo que, sendo universal, apesar de parecer regional, tem a capacidade de superar a radical falta de comunicabilidade da "experiência vivida enquanto vivida" (RICOEUR, 1976, p. 28), uma obra do discurso que é muito mais "do que uma sequência linear de frases" é, na verdade, "um processo cumulativo, holístico" (RICOEUR, 1976, p. 88). Nas palavras de Silviano Santiago, Dourado aprendeu com os grandes mestres da literatura nacional e internacional que o "apego à História e suas conjunturas direciona as obras propriamente literárias, e as transforma em expressões artísticas e definitivas da sociedade em que se inserem - e do tempo que toca aos personagens viver" (SANTIAGO, 2012, s/p).

\section{O mundo de Ópera dos mortos ou o "mundo do texto"}

Todas as alusões ao mundo "de fora" do texto apenas confirmam a ideia de que a "referência exprime a plena exteriorização do discurso, na medida em que o sentido não é só o objeto ideal intentado pelo locutor, mas a realidade efectiva visada pela enunciação" (RICOEUR, 1976, p. 91). Logo, compreender um texto nada mais é do que seguir o seu movimento do que ele diz para aquilo de que ele fala, sem esquecer que o texto fala sempre de um mundo e de um modo possível de alguém nele se orientar, com as suas dimensões sendo abertas e descortinadas pelo próprio texto (RICOEUR, 1976). O romance Ópera dos mortos é um desses mundos possíveis mencionados por Ricoeur; nele conta-se a história de três gerações de uma família mineira interiorana, sintetizando informações sobre Lucas Procópio e João Capistrano Honório Cota, respectivamente, avô e pai de Rosalina, última remanescente dessa família. O destino de Rosalina, por sua vez, encontra-se entrelaçado com o de dois outros personagens: a empregada negra e muda chamada Quiquina, zeladora dos segredos do sobrado, e o errante Juca Passarinho, caolho e contador de histórias reais e inventadas. A trama, em grande parte, aborda a relação que se estabelece entre Rosalina, Quiquina e Juca Passarinho e de que forma as decisões por eles tomadas influenciam o fim que desde o início parece inevitável. Cada um desses personagens vive e morre no relato de Autran Dourado trazendo "as marcas de sua constituição; cada um revela ou desvela os aspectos presentes em seu psiquismo, seus dramas, medos e sofrimentos" (DE PAULA, 2007, p. 33).

A casa, ou melhor, a forma como ela é descrita, também a torna um personagem, pois parece viva. Nesse sentido, pode-se perceber a presença de um estilo barroco na representação, não só do sobrado, mas também nas personalidades dos personagens, estilo que Afrânio Coutinho caracteriza como sendo:

[...] um estilo prismático, em que as impressões são comunicadas através de diversas facetas [...] uma ação é privada de sua análise imediata, aparecendo quebrada em uma multidão de impressões desconexas ou não relacionadas; tal como um raio de luz dividido por um prisma, há entre o autor e o receptor a descrição de um olho, um ouvido ou outro receptáculo sensorial do herói que influi na impressão (COUTINHO, 2004, p. 230).

O estilo barroco descrito por Coutinho pode nos levar a pensar em uma outra forma de manifestação artística, que pode ter servido de inspiração para Dourado, a ópera 
barroca. Nos seus inícios, ela era uma atividade protegida pela nobreza, mas com o fortalecimento da burguesia, a ópera barroca acabou passando dos palácios para os teatros mantidos pelos comerciantes. Esse movimento determinou uma redução da importância do coro e do número de músicos e do aparecimento de personagens cômicos ou bufos. Além disso, na ópera barroca era preciso surpreender e o cenário devia ser o mais ornamentado possível, com a cenografia assumindo uma importância que não tinha antes ${ }^{49}$.

Reunindo o comentário de Afrânio Coutinho e essa breve exposição das características da ópera barroca, pode-se notar que na configuração de Ópera dos mortos alguns desses elementos estão presentes. Elementos que são trabalhados de maneira que o mundo ficcional acaba se tornando um conjunto das referências abertas pelo texto, libertando-se não só do autor e do seu auditório original, mas também da estreiteza de uma situação dialógica que lhe permite revelar o destino do discurso como sendo capaz de projetar um mundo (RICOEUR, 1976).

A partir dessa perspectiva, pode-se reconhecer em Juca Passarinho um personagem bufo ou cômico, característico das óperas barrocas. Juca é um homem alegre, um estrangeiro, que chega à cidade contando "causos" de sua antiga vida, tendo como protagonista, além dele mesmo, seu padrinho, o major Lindolfo. Inventando e aumentando, ele acaba transformando-se, no dizer do narrador, em uma ponte entre a povo da cidade e a gente do sobrado:

Desde os primeiros dias a cidade filhou Juca Passarinho, ele era um dos nossos. De novo tentávamos construir uma ponte para o sobrado, talvez por ali a gente pudesse passar. Seria a ligação cortada, que se tentou restabelecer por ocasião das duas mortes: a de dona Genu e a de João Capistrano Honório Cota (DOURADO, 1999, p. 110).

A bufonaria de Juca Passarinho pode representar, na configuração da obra, a presença do novo, daquele que rompe, pelo menos inicialmente, com a herança de um passado que todos desejam esquecer. Seus olhos são olhos de espanto e de surpresa e, ao contrário dos moradores da cidade, ele não está "manchado". Essa é uma das razões porque Rosalina o contrata, porque para Juca Passarinho tudo era claro e limpo, "tudo dava uma sensação boa de sombra, do fresquinho que devia de estar lá dentro, de acolhimento, de paz" (DOURADO, 1999, p. 83). Entretanto, por detrás dessa aparência alegre e despreocupada, há uma personalidade que vê e sente, muitas vezes de forma inconsciente, as sombras que cercam o sobrado. Sombras que pouco a pouco vão tomando forma na figura de Rosalina, a "mulher-moça", que envolve Juca Passarinho em uma relação onde se mistura paixão, ira, rancor, tristeza e solidão.

A cenografia, característica importante da ópera barroca, está por todo o romance de Dourado, a começar pela própria descrição da casa de Honório Cota. Ela se impõe como imagem de um espaço fora do tempo. Um lugar onde estão presentes diferentes dimensões temporais, representadas, como já foi dito antes, nos relógios parados e em movimento. O sobrado é um espaço mítico que dá um sentido mais profundo a uma construção que poderia ser considerada apenas estranha, quando na verdade ela representa o passado, o presente e o futuro reunidos em um só lugar:

Ponha tento na construção, pense no barroco e nas suas mudanças, na feição do sobrado, na sua aparência inteira, apartada, suspensa (não, oh tempo, pare as suas engrenagens e areias, deixe a casa como é, foi ou era; só pra gente ver, a gente carece de ver; impossível com a sua medição destruidora, que cimenta,

${ }^{49}$ Disponível em: <http://laopera.net/historia-de-la-opera/opera-barroca〉._Acesso em: 06 jun. 2017. 
castradora); esqueça por um momento os sinais, os avisos surdos das ruínas, dos desastres, do destino (DOURADO, 1999, p. 12).

Esse convite para viajar no tempo exerce sobre o leitor uma espécie de fascínio que é difícil de romper: "Veja a casa como era e não como é ou foi agora" (DOURADO, 1999, p. 12), convida o narrador. Passado, presente e futuro unidos de forma a configurar uma narrativa que trabalha com a dimensão cronológica e não-cronológica: a primeira correspondendo à dimensão episódica da história, a segunda sendo a responsável por transformar os acontecimentos em história, um ato configurante que “consiste em 'considerar junto' as ações de detalhe ou o que chamamos de os incidentes da história" (RICOEUR, 1994, p. 104). Além disso, enquanto essa dimensão episódica puxa o tempo narrativo para o lado da representação linear, a dimensão configurante transforma "a sucessão de acontecimentos numa totalidade significante" (RICOEUR, 1994, p. 105), permitindo que a narrativa possa ser traduzida num "pensamento", que é justamente seu "assunto" ou seu "tema". Há, nesse sentido, uma inversão da "flecha temporal", inversão que aparece na trama quando o narrador convida a que se "estique bem a vista, mire o casarão como num espelho, e procure ver do outro lado, no fundo do lago, mais além do além, no fim do tempo. Recue no tempo, nas calendas, a gente vai imaginando" (DOURADO, 1999, p. 11).

Não menos bufo é o personagem de Quiquina - "uma preta gorda, baixotinha, velha, com uns fios brancos de barba no queixo" (DOURADO, 1999, p. 83) - que dentro de sua mudez vela pelo bem-estar da casa e de sua proprietária. Ela, ao contrário de Juca Passarinho, se esforça em manter tudo como está. Para Quiquina, a solidão autoimposta de Rosalina não tem mais solução e a presença do novo empregado apenas traz desequilíbrio e desconforto. Ela vê em Juca Passarinho uma ameaça, seu olho branco o tornava suspeito, pois, "ela não sabia nunca se ele estava mesmo vendo. Porque tudo nele podia ser fingimento, o homem não prestava, a gente via logo. Será que Rosalina não via? Por que não o mandava embora?" (DOURADO, 1999, p. 105). Rosalina tornase, então, o grande prêmio nesse "combate" silencioso entre Juca e Quiquina. Uma luta que pode representar o embate entre uma antiga tradição, sedimentada pelo tempo, contra uma nova que tenta se impor, na busca da superação de limites e preconceitos.

Encontra-se ainda, na configuração dessa narrativa, a presença do mito. Uma presença que contribui para que o desfecho trágico acabe sendo inevitável. Autran Dourado valese, por exemplo, do mito de Édipo, para demonstrar que, independente das voltas que a vida possa dar, é impossível ludibriar o destino. Em uma história contada por dona Vivinha, esposa do major Lindolfo, Juca Passarinho percebe que mesmo "fugindo do buraco é que a gente cai nele" (DOURADO, 1999, p. 81):

Dona Vivinha, dizia que tinha um homem que era uma vez teve um sonho muito ruim, desses que acordam a gente para salvação. A sua filhinha vai crescer, disse a voz no sonho, vai virar moça, quando ela virar moça vai dar uma coisa em você, uma idéia sem arrematação de que a gente não se livra, senão consentindo no que ela quer. Ela vai virar moça bonita, enfeitada, dengosa, uma lindeza. Mesmo não querendo, você vai acabar dormindo com ela, lhe tirando a flor (DOURADO, 1999, p. 81).

Dourado trabalha com o mito atualizando-o, sem, contudo, tirar-lhe o peso da profecia, da inevitabilidade do destino. Juca Passarinho, apesar de sentir que algo novo e perigoso está prestes a acontecer, arrisca-se e entra no sobrado. Quando conhece Rosalina mergulha em uma relação angustiante na qual se misturam, em igual medida, desejo e vergonha. Uma relação que se constrói na solidão da jovem mulher que, mesmo sem querer, vê em Juca Passarinho a voz humana que ela tanto ansiava ouvir, a voz que veio 
dar vida ao sobrado, enchendo de "música o oco do coração", "afugentando para longe as sombras pesadas em que ela, sem dar muita conta, vivia" (DOURADO, 1999, p. 90). Para Ricoeur, é a presença de horizontes potenciais de sentido que permite que os textos literários possam ser atualizados de diversos modos, como demonstra o trabalho realizado por Dourado. No seu romance todos os elementos que fazem parte do mundo são configurados, configuração determinante da qualidade de Ópera dos mortos. Nesse sentido, não é possível ignorar a forma como a linguagem é trabalhada nessa narrativa. Segundo Silviano Santiago, as obras ficcionais de Autran Dourado

se fundam na excelência da língua portuguesa e têm origem nos autênticos conflitos fundadores da nossa contemporaneidade. E desabrocham em caldo linguístico nacional e cosmopolita, segundo os contornos numa estética realista-naturalista e mítica, num desenrolar do universo humano que é espesso e vário, contraditório e milionário (SANTIAGO, 2012, s/p).

Esse trabalho é perceptível na escolha de uma linguagem que privilegia um léxico inspirado na forma de falar do povo do interior de Minas Gerais. Vê-se esse esforço na forma como a pontuação é feita, na construção dos diálogos e na maneira como o narrador entra e sai da história, ora acrescentando informações, ora aumentando ainda mais a ambiguidade da narrativa. $O$ texto de Dourado tem uma dupla qualidade: permite ao leitor conhecer a fundo o que vai na consciência de seus personagens ao mesmo tempo que o obriga a redobrar a atenção para compreender o que não está sendo dito ou revelado. Todos esses recursos acabam proporcionando um alargamento do campo do drama humano, ao mesmo tempo que adentra no passado patriarcal da sociedade brasileira (SANTIAGO, 2012). Portanto, no mundo de Ópera dos mortos, o texto configura-se enquanto todo e enquanto totalidade, podendo-se comparar a um objeto "que é possível ver a partir de vários lados, mas nunca de todos os lados ao mesmo tempo" (RICOEUR, 1976, p. 89).

\section{O mundo do leitor da Ópera dos mortos ou o "mundo da refiguração"}

Para Ricoeur, seguir uma história é sempre atualizá-la na leitura, pois o ato de ler "acompanha o jogo entre a inovação e a sedimentação dos paradigmas que esquematizam a tessitura da intriga" (RICOEUR, 1994, p. 118). Desse modo, o ato da leitura coloca em evidência a fusão de dois horizontes, o do texto e o do leitor, de maneira que o segundo nunca recebe apenas o sentido da obra, mas toda a experiência que ela faz chegar à linguagem e, consequentemente, ao mundo e sua temporalidade (RICOEUR, 1994).

Obras literárias como Ópera dos mortos teriam como propósito, então, ampliar o horizonte do leitor, produzindo imagens de uma realidade amplificada e, portanto, rica em significados. O texto funcionaria "como uma partitura musical e o leitor como maestro que segue as instruções da notação" (RICOEUR, 1976, p. 87). Esse processo implicaria a capacidade de relacionar a mesma frase de modos diferentes, pois no ato de ler está implícito um tipo específico de unilateralidade que fundamenta o caráter conjectural da interpretação (RICOEUR, 1976).

Ópera dos mortos, desde a sua publicação em 1967, já passou por diferentes leituras, permitindo não só um alargamento do círculo de comunicação, mas a abertura de um espaço para que leitores potenciais possam realizar suas próprias interpretações da obra, pois é a resposta do público leitor que "torna o texto importante e, por conseguinte, significativo" (RICOEUR, 1976, p. 43). Silviano Santiago, ao reconhecer que a leitura de Dourado é fácil, mas que sua interpretação não o é, estabelece uma distinção entre o 
público leitor leigo e o especializado. Para o crítico mineiro, a obra de Dourado está construída de tal modo que os conflitos fundadores da literatura e arte moderna acabam exigindo uma leitura que requer do estudioso a força só concedida aos amantes da cultura (SANTIAGO, 2012, s/p). Será essa afirmação correta? Para responder a essa questão poderíamos recorrer a Ricoeur quando ele indaga "o que é que num texto se deve compreender - e, por conseguinte, apropriar?” (RICOEUR, 1976, p. 104). A resposta do filósofo francês é de que

aquilo de que importa apropriar-se é o sentido do próprio texto, concebido de um modo dinâmico como a direcção do pensamento aberta pelo texto. Por outras palavras, aquilo de que importa apropriar-se nada mais é do que o poder de desvelar um mundo, que constitui a referência do texto. Desta maneira, estamos o mais longe possível do ideal romântico de coincidir com uma psique alheia (RICOEUR, 1976, p. 104).

A leitura de Ópera dos mortos permite esse desvelamento de um mundo que está acessível a qualquer leitor potencial. Um mundo no qual poder-se-á encontrar referências ao mundo "de fora", mas que em si mesmo constitui-se em mundo próprio, que transita no que Ricoeur denominou de "plurivocidade", típica das obras complexas do discurso. Desse modo, o texto fica aberto a múltiplas interpretações, já que está também aberto a um número indefinido de leitores, quer sejam eles leigos ou especializados. É claro que um leitor leigo, dentro de seu próprio horizonte de expectativas, irá realizar interpretações que serão diferentes daquelas feitas por especialistas, mas isso não impede que ele encontre na obra um sentido ou um significado que lhe é próximo.

O fato é que a leitura de Ópera dos mortos (como toda a boa literatura) tira o leitor de sua passividade, exige dele um trabalho de interpretação no qual o processo da leitura é "movido pulsionalmente por algo que lhe é externo e o provoca, determinando suas escolhas, suas marcações e deslizamentos a partir do material escrito" (DE PAULA, 2007, p. 40). Esse processo do qual o leitor participa ativamente é que permite que ele acompanhe e compreenda a profundidade da agonia de Rosalina, seu interesse pelo único homem com o qual pode ter algo que se assemelha a uma relação e o seu fim trágico, quando, desconectada da realidade, deixa o sobrado para sempre:

E ela sorria, meu Deus, a gente viu depois de muitos anos Rosalina sorrir pela primeira vez. Ela sorria feito se fosse para a gente. Mas sabíamos, não era para nós que ela sorria: era um sorriso meio abobalhado, para ninguém. Ela parecia não nos reconhecer, e no entanto sorria, os olhos vidrados como que não viam, e era para a gente que ela mirava, ela sorria (DOURADO, 1999, p. 247).

O leitor não só vê o drama se descortinar diante dele, como se torna capaz, inclusive, de imaginar a música que poderia acompanhá-lo. Consegue sentir a dor e a amargura de Juca Passarinho, assim como ouvir o murmurinho do povo da cidade que se aglomera no sobrado para ver a saída definitiva de Rosalina. E, no final, mantendo a respiração em suspenso, o leitor também pode "ver" o último dos relógios, a pêndula, sendo parado por Quiquina, uma repetição já anunciada, mas que mesmo assim surpreende:

Quando a gente já andava meio sem esperança de qualquer novidade de monta, veio alguém com a notícia de que Quiquina tinha descido a escada, ido até a copa, parado a pêndula. Mas ninguém viu, como foi que viram? Porque de repente a pêndula parou. A gente esperava tudo repetido, mas não assim tão igualzinho que nem relógio de repetição (DOURADO, 1999, p. 244).

O leitor Autran Dourado também está presente em Ópera dos mortos, não apenas na sua atualização dos mitos, mas em algumas citações indiretas a grandes clássicos da literatura ocidental. Esse é o caso, por exemplo, da sua descrição do coronel Honório 
Cota. Inspirado na obra de Cervantes, o coronel torna-se o "dom quixote desmiolado" (DOURADO, 1999, p. 34), apelido malicioso dado por seus inimigos políticos, mas que, ao contrário do que se possa pensar, "não o amofinava", pois o fazia lembrar de uma

gravura antiga em que aparecia um cavaleiro alto e comprido feito ele, descarnado e enxuto de cara, a lança em riste. Procurou nos guardados da mãe o livro e a gravura, não achou, e não achando, juntou a memória à imaginação e criou para si uma nova figura. Se a gente reparasse melhor (a gente nunca repara nessas ocasiões, só depois), tinha mesmo uns ares do Caballero de la Fé, também da Triste Figura (DOURADO, 1999, p. 34).

Aqui se percebe o movimento do leitor Dourado apropriando-se de um personagem de outra obra para, com suas características, construir seu próprio personagem. Um movimento que não tem relação com qualquer tipo de apelo de pessoa a pessoa, mas que, segundo Ricoeur, aproxima-se antes do que Hans Georg Gadamer chamou de "fusão de horizontes: o horizonte do mundo do leitor confunde-se com o horizonte do mundo do escritor. E a idealidade do texto é o vínculo mediador neste processo de fusão de horizontes" (RICOEUR, 1976, p. 105). A consequência desse movimento é que o texto de Dourado acaba transcendendo "época e circunstancias históricas, para apresentar o ser humano regido por leis universais, tão ricas e rigorosas quanto, por exemplo, a figura de Fedra na peça homônima de Racine, ou o complexo de Édipo, em Hamlet" (SANTIAGO, 2012, s/p).

Desse modo, o leitor de Autran Dourado vê-se diante de um mundo no qual é um participante ativo, pois nesse processo de comunicação, o sujeito leitor se vê forçado a ressignificar o texto, resgatando-o do esquecimento, a partir de sucessivas atualizações. E apenas uma literatura de qualidade, como é o caso de Ópera dos mortos, é capaz de, no ato da leitura, responder não só as preocupações mais profundas do leitor, como permitir que ele alcance um "prazer próprio" construído, em primeira instância, dentro do texto (RICOEUR, 1994).

\section{Considerações finais: a fusão de mundos na obra Ópera dos mortos}

Quando Ricoeur procura explicar a mimese ele o faz a partir de uma pesquisa da mediação entre tempo e narrativa. Na mimese I tem-se o "mundo referencial" e todas as suas circunstâncias influenciando na criação do texto, pois quando o autor escreve, ele o faz sobre algo que existe. Na mimese II tem-se o "mundo do texto" no qual a temporalidade pode assumir diferentes dimensões sempre com objetivo de representar criativamente acontecimentos ou incidentes individuais. E, finalmente, na mimese III tem-se uma intersecção entre o "mundo do texto" e o "mundo do leitor". Como o texto comporta buracos, lacunas e zonas de indeterminação, cabe ao ato de leitura realizar a operação que conjuga a mimese III e a mimese II.

Na análise de Ópera dos mortos foi possível perceber a presença desse "tríplice tempo", representado pelas mimeses I, II e III. A existência de elementos extraídos da realidade mineira, ou seja, da realidade do autor, é evidente na escolha das imagens e dos conflitos que constituem a obra. Desde a menção a um fenômeno geológico, típico da região mineira, até o registro das disputas políticas que sempre estiverem presentes na sociedade da qual o autor fez parte, confirmam a hipótese de Ricoeur quando, ao se referir ao "mundo referencial", o vê como algo que deve existir para que algo se possa identificar, pois o "sentido é, por assim dizer, atravessado pela intenção de referência do locutor" (RICOEUR, 1976, p. 32). 
No entanto, o "mundo do texto" não pode ser visto como um simples reflexo (ou retrato) da realidade externa. Na configuração de Ópera dos mortos (e de todas as obras literárias) está em questão a obra como um discurso que, apesar de não poder deixar de ser acerca de alguma coisa, é uma linguagem submetida às regras de uma espécie de artesanato, onde o autor "não é só falante, mas também fazedor da obra que é a sua obra" (RICOEUR, 1976, p. 44).

O processo de configuração de Ópera dos mortos já começa pela escolha da epígrafe, quando o autor cita, Heráclito - "O deus de quem é o oráculo de Delfos não diz nem oculta nada: significa". Nessa escolha está implícito um alerta ao leitor: ele estará diante de um drama no qual o destino terá um papel importante, não só na constituição do enredo, mas, principalmente, na caracterização de seus personagens. Isso fica claro na forma como a história é apresentada, na opção por uma linguagem própria da região de origem do autor e na presença de um narrador, que aparece e desaparece, explicando o que é preciso ver, trabalhando o dito e o não dito de forma a criar uma atmosfera que se assemelha muito ao drama teatral. Essa sensação de estar-se diante de um "espetáculo" que está prestes a começar fica ainda mais evidente quando, após todas as explicações terem sido dadas no primeiro capítulo, "O sobrado", o narrador pede ao "público": "E então, silêncio. Rosalina vai chegar na janela" (DOURADO, 1999, p. 18). Frase que está entre parênteses como acontece com as rubricas ${ }^{50}$ dos textos teatrais. Contudo, Ópera dos mortos não é uma peça, mas um romance. Uma diferença importante quando se pensa no tempo da narrativa e na participação do leitor.

Em relação ao tempo percebe-se essa distensão típica das narrativas literárias, com o leitor indo e vindo na linha temporal, no que Ricoeur denominou de "tríplice presente", quando passado, presente e futuro misturam-se para configurar a obra, tornando-a atemporal. Processo que, segundo Ricoeur, só é possível dentro do texto, pois "narramos as coisas que consideramos verdadeiras e predizemos acontecimentos que ocorrem tal como os havíamos antecipado" (RICOEUR, 1994, p. 26). Em Ópera dos mortos essa manipulação da linha temporal é clara, pois histórias são contadas como se presente, passado e futuro fossem uma única entidade, fora do tempo medido pelo relógio ou pelo calendário: "Agora chegou a vez do tempo passar, o tempo passou. Chegou a vez do tempo passar para que outra morte se suceda e a gente possa novamente voltar ao velho sobrado" (DOURADO, 1999, p. 40).

A presença ativa do leitor nesse processo é fundamental, pois dele depende a recuperação dos diferentes sentidos de uma obra, que só ocorre a partir das diversas releituras realizadas ao longo do tempo. Cabe, então, ao leitor descobrir o sentido do texto, compreender que não é a situação inicial do discurso que importa, mas "o que aponta para um mundo possível, graças à referência não ostensiva do texto" (RICOEUR, 1976, p. 99). Assim, pode-se dizer que um grande texto, além de permitir que se perceba as marcas do tempo no qual foi escrito, também possibilita ao contemporâneo encontrar respostas para as questões de seu próprio tempo. Nesse processo o texto não só se reatualiza, mas também se descontextualiza, movimento que só ocorre por meio da leitura

Em Ópera dos mortos o leitor deve ir além do mito, além dos silêncios dos personagens, precisa mergulhar em suas consciências para encontrar nelas as respostas aos dilemas que atormentam o homem desde sempre. Portanto, pode-se concluir essa análise concordando com Ricoeur quando diz que se "a referência do texto é projecto de um mundo, então, não é o leitor que primeiramente a si mesmo se projecta. O leitor é antes

\footnotetext{
${ }^{50}$ As rubricas (ou didascálias) são anotações feitas pelo autor do texto que determinam ações, intenções, a movimentação em cena, às vezes detalhes do cenário, iluminação, sonoplastia, etc. Disponível em: <http://www.desvendandoteatro.com/texto.htm>. Acesso em: 23 jun. 2017.
} 
alargado na sua capacidade de auto projeção, ao receber do texto um novo modo de ser" (RICOEUR, 1976, p. 106).

\section{REFERÊNCIAS}

COUTINHO, Afrânio. A Literatura no Brasil. 7ed. São Paulo: Global, 2004.

DOURADO, Autran. Ópera dos mortos. Rio de Janeiro: Rocco, 1999.

HOUAISS, Antonio. Dicionário Houaiss. Rio de Janeiro: Ed. Objetiva, 2009.

PAULA, Janaína Rocha de. As engrenagens do silêncio. Revista Psychê, São Paulo, ano XI, n 21, p. 31-4, jul-dez, 2007.

RICOEUR, Paul. Teoria da interpretação. O discurso e excesso de significação.

Tradução de Artur Morão. Lisboa: Edições 70, 1976.

RICOEUR, Paul. Tempo e Narrativa. Tomo I. Tradução Constança Marcondes Cesar. Revisão Marina Appenzeller. Campinas, SP: Papirus, 1994.

SANTIAGO, Silviano. Mineiro Autran Dourado produziu uma narrativa original e cosmopolita. Disponível em: <http://cultura.estadao.com.br/noticias/geral,mineiroautran-dourado-produziu-uma-narrativa-original-e-cosmopolita,940804>. Acesso em: 02 jun. 2017

SOUZA. Maria Eneida de. As Minas Douradas da Ficção. Belo Horizonte: Centro de Estudos Literários, 1996. 